\title{
Nerve function impairment in leprosy at diagnosis and at completion of MDT: a retrospective cohort study of 786 patients in Bangladesh
}

\author{
J. H. RICHARDUS*, K. M. FINLAY*,
}

R. P. CROFT* \& W.C.S. SMITH†

*The Leprosy Mission - Bangladesh, House 4, Road 9, Block G, Banani, 1213 Dhaka, Bangladesh; $\uparrow$ University of Aberdeen, Department of Public Health, Medical School, Polwarth Building, Foresterhill, Aberdeen AB9 2ZD, Scotland, UK

\section{Accepted for publication 30 July 1996}

Summary This retrospective cohort study includes all new leprosy patients registered for multidrug therapy (MDT) in 1990 at the Danish-Bangladesh Leprosy Mission project in Bangladesh. The main objective was to determine the extent of nerve function impairment (NFI) at diagnosis and at completion of MDT, and to identify opportunities for intervention and their relative impact on the prevention of disabilities (POD).

A total of 786 patients were included; 486 males and 300 females. There were $315 \mathrm{~PB}$, and $471 \mathrm{MB}$ patients. In terms of the WHO leprosy disability grading system, at the time of diagnosis $31 / 315(9 \cdot 8 \%)$ had grade 1 or grade 2 disability in the PB group, and $177 / 471(37.6 \%)$ in the MB group. The incidence rate of NFI during MDT was 3.5 per 100 person years at risk (PYR) in the PB group, and 7.5 per 100 PYR in the MB group. In the MB group 37 (7.9\%) previously normal patients sustained NFI during MDT, whilst $19(4 \cdot 0 \%)$ with NFI at diagnosis showed complete recovery at completion of MDT. The most commonly involved nerves were the ulnar (motor function) and the posterior tibial nerves (sensibility). Reversal reactions were observed in $0.6 \%$ of the PB patients during MDT, giving an incidence rate of 1 per $100 \mathrm{PYR}$. The percentage of MB patients diagnosed with reversal during MDT was $14 \cdot 2 \%$, giving an incidence rate of 6 per $100 \mathrm{PYR}$. The percentage of MB patients diagnosed with ENL during MDT was $2 \cdot 1 \%$, with an incidence rate of 1 per 100 PYR.

It was concluded that early detection of new cases of leprosy would prevent disabilities in more than $30 \%$ of all patients, thus having the highest impact in the quest for the prevention of disabilities. POD activities during and after MDT will prevent disabilities in approximately $10 \%$ of all cases. This study also indicates that treatment with prednisolone is effective and should be available at field level for all patients with recent NFI. 


\section{Introduction}

Leprosy can lead to disability and handicap through peripheral neuropathy. The importance of prevention of disability (POD) activities as integral part of leprosy control programmes is being increasingly recognized. ${ }^{1}$ Despite the success of MDT in curing patients from leprosy infection, if the occurrence of disability and handicap cannot be prevented, treatment remains a failure as far as the patient is concerned. Gradually more information concerning the aetiology, incidence, risk factors and treatment of peripheral neuropathy in leprosy patients is becoming available, although there are still many gaps. ${ }^{2,3}$ New techniques for early detection of nerve function impairment (NFI), imperative for successful therapeutical intervention, have been developed and tested. ${ }^{3}$ The challenge at present is to translate new knowledge and techniques into simple and practical methods for implementation in field programmes so that the majority of leprosy patients may benefit. This requires further insight into the epidemiology of NFI, and more extensive field trials of simple and standardized methods of detection and treatment.

This study is primarily concerned with the incidence of NFI at the time of diagnosis (registration) and at completion of MDT, within the context of a well established (vertical) leprosy control programme covering three highly leprosy endemic districts of north-west Bangladesh. The main objective is to determine retrospectively the extent of the problem of NFI at diagnosis and at completion of MDT, and to identify opportunities of intervention and their relative impact on prevention of disabilities.

\section{Methods}

The study was conducted at the Danish-Bangladesh Leprosy Mission (DBLM) in Nilphamari, in the north-west of Bangladesh. DBLM is a private organization involved in a vertical leprosy programme situated in a highly endemic area. ${ }^{4}$ At the time of recruitment of patients to this study (1990) the programme covered three districts with a total population of approximately 4 million.

This study is a retrospective cohort study. The data was generated within a busy (routine) field programme, primarily by paramedical staff. The project has maintained good quality charts on all patients over a long period of time. MDT coverage was virtually $100 \%$ and over $95 \%$ of patients completed MDT within the required time frame. In spite of this it had to be accepted that data might not be completely accurate and consistent, and only basic descriptive statistics are applied as appropriate.

Included in this analysis were all new, previously untreated, leprosy patients first registered in 1990 for treatment with multidrug therapy (MDT). All patient charts were reviewed and the following data compiled: age, sex and leprosy classification (MB, multibacillary; PB, paucibacillary). In addition the results of body charting, voluntary muscle testing (VMT), and sensory testing (ST) at the time of registration and completion of MDT were reviewed. ST was carried out using a ball-point pen as described by Jean Watson; ${ }^{5} 12$ standard points were allotted to each hand, 11 to each foot. VMT was carried out using the revised MRC scale (Table 1). ${ }^{2}$ Special note was taken of the duration of nerve function impairment at the time of registration, which 
Table 1. MRC score and muscles tested.

\begin{tabular}{ll}
\hline & $\begin{array}{l}\text { MRC } \\
\text { score }\end{array}$ \\
Muscle strength finding & 5 \\
Full ROM*, full resistance & 4 \\
Full ROM, reduced resistance & 3 \\
Full ROM, no resistance & 2 \\
Reduced ROM, some joint movement & 1 \\
Flicker only & 0 \\
Full paralysis & Muscle and movement \\
Nerve & \\
\hline (Common) Peroneal/Lateral popliteal & Dorsiflexion of foot \\
Radial & Extension of wrist \\
Median & Abduction of thumb (abductor pollicis brevis) \\
Ulnar & Abduction of little finger (abductor digiti minimi) \\
Lagophthalmos (Facial nerve) & Tight closure of eye (orbicularis oculi) \\
& \\
\hline
\end{tabular}

*ROM, range of movement

nerves were involved, the occurrence of reactions (type I and II), and whether the patients had received prednisolone during their time on MDT.

Nerve function impairment (NFI) is defined as a clinically detectable impairment of motor, sensory or autonomic nerve function. ${ }^{6}$ If NFI has existed 6 months or less, it is considered to be 'recent' (RNFI). Treatment of the underlying neuritis with corticosteroids is usually considered indicated within this time span. It is practice at DBLM to register NFI according to the WHO recommended disability grading scale of impairments in leprosy. ${ }^{7}$ The term 'normal' is used when there is no NFI as detectable with the applied sensory and voluntary muscle tests. 'Abnormal' includes WHO disability grading 1 and 2 .

\section{Results}

A total of 786 patients are included in this study; 486 males and 300 females (male: female ratio is $1.6: 1$ ). The total number of $\mathrm{MB}$ patients is 471 and the total number of $\mathrm{PB}$ patients is $315(\mathrm{MB}: \mathrm{PB}$ ratio is $1 \cdot 5: 1)$. The distribution according to age is given in Table 2 .

Tables 3 and 4 show the disability status at registration and at release from treatment (RFT) of PB and MB patients respectively. Also included in the tables is information about the occurrence of recent nerve function impairment (RNFI) at the time of registration and during treatment with MDT, and if prednisolone was provided.

Of the PB patients, $284(90 \cdot 2 \%)$ had no NFI at registration and of these, $279(88 \cdot 6 \%)$ had no NFI at RFT. A total of 6 patients were diagnosed with RNFI during MDT. One was treated with prednisolone and recovered completely. The other 5 patients did not receive prednisolone and remained with NFI at RFT. In 25 of the 31 patients who had NFI at registration, the impairments had existed longer than 6 months. Of the 6 remaining patients, none received prednisolone (although this would probably have 
Table 2. General data of all new leprosy patients who started MDT in 1990.

\begin{tabular}{|c|c|c|c|c|c|c|}
\hline \multirow[b]{2}{*}{ Age in years } & \multicolumn{2}{|c|}{ PB } & \multicolumn{2}{|c|}{ MB } & \multirow{2}{*}{$\begin{array}{c}\text { Total } \\
\text { PB }\end{array}$} & \multirow{2}{*}{$\begin{array}{c}\text { Total } \\
\text { MB }\end{array}$} \\
\hline & Male & Female & Male & Female & & \\
\hline 0 to 9 & 26 & 14 & 21 & 12 & 40 & 33 \\
\hline 10 to 14 & 23 & 25 & 23 & 12 & 48 & 35 \\
\hline 15 to 19 & 24 & 12 & 21 & 16 & 36 & 37 \\
\hline 20 to 29 & 38 & 29 & 59 & 28 & 67 & 87 \\
\hline 30 to 39 & 26 & 25 & 87 & 40 & 51 & 127 \\
\hline 40 to 49 & 15 & 22 & 45 & 24 & 37 & 69 \\
\hline 50 to 59 & 9 & 12 & 28 & 24 & 21 & 52 \\
\hline$\geq 60$ & 14 & 1 & 27 & 4 & 15 & 31 \\
\hline Total & 175 & 140 & 311 & 160 & 315 & 471 \\
\hline
\end{tabular}

been indicated). However, 4 of these patients apparently recovered spontaneously and were registered with no NFI at the time of completion of MDT.

Table 4 shows similar data for the MB group of patients. Only $294(62 \cdot 4 \%)$ of this group had no NFI at the time of registration. A total of 53 developed RNFI during MDT of which 40 received prednisolone. Recovery was complete in 16 of these patients. The remaining 13 did not receive prednisolone and were all left with NFI at RFT. One hundred and sixteen $(24 \cdot 6 \%)$ had NFI of longer than 6 months, and no recovery was found in this group. The remaining $61(13.0 \%)$ were observed with NFI at registration, but of short duration. Of this group 50 received prednisolone and 11 had recovered completely at the time of RFT. Again there are 8 patients who had NFI at registration and did not receive any prednisolone during MDT, who showed recovery at the time of RFT. The percentages of patients at registration and RFT with NFI in the PB and MB

Table 3. Disability status at registration and release from treatment (RFT) of MDT of PB leprosy patients.

\begin{tabular}{|c|c|c|c|c|c|c|}
\hline \multirow{2}{*}{$\begin{array}{l}\text { Status at } \\
\text { registration }\end{array}$} & \multirow{2}{*}{$\begin{array}{l}\text { RNFI* } \\
+/-\end{array}$} & \multirow{2}{*}{$\begin{array}{l}\text { Pred } \dagger \\
+/-\end{array}$} & \multirow{2}{*}{$\begin{array}{l}\text { Status at } \\
\text { RFT }\end{array}$} & \multicolumn{2}{|c|}{ No of patients } & \multirow[b]{2}{*}{ Total } \\
\hline & & & & Male & Female & \\
\hline \multirow[t]{5}{*}{ Normal } & - & na & Normal & 154 & 124 & 278 \\
\hline & + & + & Normal & 1 & 0 & 1 \\
\hline & + & + & Abnormal & 0 & 0 & 0 \\
\hline & + & - & Normal & 0 & 0 & 0 \\
\hline & + & - & Abnormal & 2 & 3 & 5 \\
\hline \multirow[t]{5}{*}{ Abnormal } & - & nał & Abnormal§ & 13 & 12 & 25 \\
\hline & + & + & Normal & 0 & 0 & 0 \\
\hline & + & + & Abnormal & 0 & 0 & 0 \\
\hline & + & - & Normal & 3 & 1 & 4 \\
\hline & + & - & Abnormal & 2 & 0 & 2 \\
\hline Total & & & & 175 & 140 & 315 \\
\hline
\end{tabular}

*RNFI, recent nerve function impairment;

$\dagger$ Pred, prednisolone treatment received during treatment with MDT;

$\ddagger$ na, not applicable;

$\S$ This group had nerve damage of more than 6 months duration. 
Table 4. Disability status a tregistration and release from treatment (RFT) of MDT of MB leprosy patients.

\begin{tabular}{|c|c|c|c|c|c|c|}
\hline \multirow{2}{*}{$\begin{array}{l}\text { Status at } \\
\text { registration }\end{array}$} & \multirow{2}{*}{$\begin{array}{l}\text { RNFI* } \\
+/-\end{array}$} & \multirow{2}{*}{$\begin{array}{l}\text { Pred } \dagger \\
+/-\end{array}$} & \multirow{2}{*}{$\begin{array}{l}\text { Status at } \\
\text { RFT }\end{array}$} & \multicolumn{2}{|c|}{ No of patients } & \multirow[b]{2}{*}{ Total } \\
\hline & & & & Male & Female & \\
\hline \multirow[t]{5}{*}{ Normal } & - & nał & Normal & 142 & 98 & 241 \\
\hline & + & + & Normal & 11 & 5 & 16 \\
\hline & + & + & Abnormal & 20 & 4 & 24 \\
\hline & + & - & Normal & 0 & 0 & 0 \\
\hline & + & - & Abnormal & 8 & 5 & 13 \\
\hline \multirow[t]{5}{*}{ Abnormal } & - & na $\ddagger$ & Abnormal§ & 86 & 30 & 116 \\
\hline & + & + & Normal & 7 & 4 & 11 \\
\hline & + & + & Abnormal & 27 & 12 & 39 \\
\hline & + & - & Normal & 7 & 1 & 8 \\
\hline & + & - & Abnormal & 3 & 0 & 3 \\
\hline Total & & & & 311 & 160 & 471 \\
\hline
\end{tabular}

See Table 3 for notation.

groups are summarized in Tables 5 and 6. PB and MB patients with no NFI at detection had a $1.8 \%$ and $14.4 \%$ risk of having NFI at RFT. The proportion of PB patients with NFI at diagnosis is $9.8 \%$ compared to $10.2 \%$ at RFT, the corresponding figures for MB were $37 \cdot 6 \%$ and $41 \cdot 4 \%$.

Table 7 gives a breakdown of the nerves showing NFI at the time of registration, and the initially normal nerves at registration that sustained NFI during treatment and were still abnormal at the time of RFT. The percentages represent the number of patients with the particular nerves involved. This means that if there is bilateral nerve involvement, it is only counted once. Finally, Table 8 shows the number of patients with observed leprosy reactions in both the PB group (reversal, or Type I, reaction only) and the MB group (both reversal and ENL (Type II) reactions).

\section{Discussion}

In terms of the WHO leprosy disability grading system, it was found that at the time of registration a total of $31 / 315(9.8 \%)$ had grade 1 or grade 2 disability in the PB group, and $177 / 471(37 \cdot 6 \%)$ in the MB group (Tables 5 and 6). The figures in the PB group for

Table 5. Summary of disability status of $\mathrm{PB}$ patients at registration and RFT.

\begin{tabular}{lccc}
\hline & \multicolumn{3}{c}{ At RFT } \\
\cline { 2 - 4 } At registration & Normal & Abnormal & Total \\
\hline Normal & $279(88 \cdot 6 \%)$ & $5(1 \cdot 6 \%)$ & $284(90 \cdot 2 \%)$ \\
Abnormal & $4(1 \cdot 3 \%)$ & $27(8 \cdot 6 \%)$ & $31(9 \cdot 8 \%)$ \\
Total & $283(89 \cdot 8 \%)$ & $32(10 \cdot 2 \%)$ & $315(100 \%)$ \\
\hline
\end{tabular}


Table 6. Summary of disability status of MB patients at registration and RFT.

\begin{tabular}{lccc}
\hline & \multicolumn{3}{c}{ At RFT } \\
\cline { 2 - 4 } At registration & Normal & Abnormal & Total \\
\hline Normal & $257(54 \cdot 6 \%)$ & $37(7 \cdot 9 \%)$ & $294(62 \cdot 4 \%)$ \\
Abnormal & $19(4 \cdot 0 \%)$ & $158(33 \cdot 5 \%)$ & $177(37 \cdot 6 \%)$ \\
Total & $276(58 \cdot 6 \%)$ & $195(41 \cdot 4 \%)$ & $471(100 \%)$ \\
\hline
\end{tabular}

males was $18 / 175(10 \cdot 3 \%)$ and for females $13 / 140(9 \cdot 3 \%)$. In the MB group more males had disability; $130 / 311(41 \cdot 8 \%)$ against females $47 / 160(20 \cdot 4 \%)$. The incidence rate of NFI during MDT was approximately 3.5 per 100 person years at risk (PYR) in the PB group, and approximately $7 \cdot 5$ per 100 PYR in the MB group. The incidence rate of disability (or crude disability attack rate) in patients treated with MDT has recently been estimated to be between 1 to 5 per $100 \mathrm{PYR}^{8}$ The findings of this paper seem to be higher, but this is caused by the fact that the figures in this paper include both WHO grade 1 and 2 disability, whilst in the referred article only grade 2 is taken into consideration. This is the case in most studies, since grade 2 (visible deformity) is a more objective parameter, but it does make comparison difficult at times.

The overall disability status before and after MDT in the PB group hardly changed; $9.8 \%$ at registration and $10 \cdot 2 \%$ at RFT. Although $5(1 \cdot 6 \%)$, previously normal patients developed NFI during the 6- to 9-months period of MDT, $4(1 \cdot 3 \%)$ other patients who had NFI at registration had apparently recovered at RFT, interestingly enough without the benefit of treatment with corticosteroids. In the MB group, this picture is more dramatic: 37 (7.9\%) previously normal patients sustained nerve damage during the 2 to 3 year period of MDT with NFI recorded at RFT. At the same time $19(4 \cdot 0 \%)$ patients with NFI at registration showed complete recovery at RFT.

In the early 1990s, it was still practice within the project to provide treatment with corticosteroids to hospitalized patients only. Patients with a clear indication because of leprosy reactions and/or signs of RNFI were advised to be admitted, but unfortunately this advice could not be followed by all patients for various reasons. The treatment

Table 7. Incidence of nerve involvement.

\begin{tabular}{lcc}
\hline & $\begin{array}{c}\text { Abnormal at } \\
\text { registration } \\
(n=208) \\
(\%)\end{array}$ & $\begin{array}{c}\text { Normal at registration, } \\
\text { abnormal at RFT } \\
(n=42) \\
(\%)\end{array}$ \\
\hline Peroneal nerve (strength) & 14 & 4 \\
Radial nerve (strength) & 3 & 3 \\
Median nerve (strength) & 22 & 6 \\
Ulnar nerve (strength) & 47 & 39 \\
Lagophthalmus & 3 & 1 \\
Sole sensory loss & 73 & 16 \\
Palm sensory loss & 55 & \\
\hline
\end{tabular}


Table 8. Incidence of reversal (type 1) reaction and erythema nodosum leprosum (ENL or type 2 reaction) in $\mathrm{PB}$ and $\mathrm{MB}$ patients, with age-gender specific rates (\%).

\begin{tabular}{|c|c|c|c|c|c|c|c|c|c|c|c|}
\hline \multirow{2}{*}{$\begin{array}{l}\mathrm{PB}(N=315) \\
\text { Age in years }\end{array}$} & \multicolumn{6}{|c|}{ Reversal reaction } & & & & & \\
\hline & Male & $(\%)$ & Female & $(\%)$ & Total & $(\%)$ & & & & & \\
\hline 0 to 9 & 1 & $(3 \cdot 8)$ & 0 & & 1 & $(2 \cdot 5)$ & & & & & \\
\hline 10 to 14 & 0 & & 1 & $(4 \cdot 0)$ & 1 & $(2 \cdot 1)$ & & & & & \\
\hline 15 to 19 & 0 & & 0 & & 0 & & & & & & \\
\hline 20 to 29 & 0 & & 0 & & 0 & & & & & & \\
\hline 30 to 39 & 0 & & 0 & & 0 & & & & & & \\
\hline 40 to 49 & 0 & & 0 & & 0 & & & & & & \\
\hline 50 to 59 & 0 & & 0 & & 0 & & & & & & \\
\hline$\geq 60$ & 0 & & 0 & & 0 & & & & & & \\
\hline \multirow[t]{2}{*}{ Total } & 1 & $(0 \cdot 6)$ & 1 & $(0 \cdot 7)$ & 2 & $(0 \cdot 6)$ & & & & & \\
\hline & \multicolumn{6}{|c|}{ Reversal reaction } & \multicolumn{5}{|c|}{ ENL reaction } \\
\hline $\begin{array}{l}\text { MB }(N=471) \\
\text { Age in years }\end{array}$ & Male & $(\%)$ & Female & $(\%)$ & Total & $(\%)$ & Male & $(\%)$ & Female & Total & $(\%)$ \\
\hline 0 to 9 & 2 & $(9 \cdot 5)$ & 1 & $(8 \cdot 3)$ & 3 & $(9 \cdot 1)$ & 0 & & 0 & 0 & \\
\hline 10 to 14 & 4 & $(17 \cdot 4)$ & 3 & $(25 \cdot 0)$ & 7 & $(20 \cdot 0)$ & 1 & $(4 \cdot 3)$ & 0 & 1 & \\
\hline 15 to 19 & 3 & $(14 \cdot 3)$ & 4 & $(25 \cdot 0)$ & 7 & $(18 \cdot 9)$ & 1 & $(4 \cdot 8)$ & 0 & 1 & \\
\hline 20 to 29 & 11 & $(18 \cdot 6)$ & 4 & $(14 \cdot 3)$ & 15 & $(17 \cdot 2)$ & 1 & $(1 \cdot 7)$ & 0 & 1 & \\
\hline 30 to 39 & 11 & $(12 \cdot 6)$ & 7 & $(17 \cdot 5)$ & 18 & $(14 \cdot 2)$ & 5 & $(5 \cdot 7)$ & 0 & 5 & \\
\hline 40 to 49 & 6 & $(13 \cdot 3)$ & 6 & $(25 \cdot 0)$ & 12 & $(17 \cdot 4)$ & 1 & $(2 \cdot 2)$ & 0 & 1 & \\
\hline 50 to 59 & 2 & $(7 \cdot 1)$ & 2 & $(8 \cdot 3)$ & 4 & $(7 \cdot 7)$ & 0 & & 0 & 0 & \\
\hline$\geq 60$ & 2 & $(7 \cdot 4)$ & 0 & & 2 & $(6 \cdot 5)$ & 1 & $(3 \cdot 7)$ & 0 & 1 & \\
\hline Total & 41 & $(13 \cdot 2)$ & 26 & $(16 \cdot 3)$ & 67 & $(14 \cdot 2)$ & 10 & $(3 \cdot 2)$ & 0 & 10 & $(2 \cdot 1)$ \\
\hline
\end{tabular}

regimens with prednisolone in hospital were individualized, and varied considerably per patient. An evaluation of the impact of corticosteroids is therefore not possible. In this paper it is just simply recorded if a patient at any time during MDT received prednisolone. Nevertheless, it is interesting to see what happened to patients who had RNFI, especially in the MB group. A total of 40 patients with RNFI received prednisolone (any regimen). Of these $16(40 \%)$ recovered completely. Also in the group of 50 patients who had RNFI at registration and received prednisolone during MDT, there was complete recovery in $11(22 \%)$ patients. It should be noted that complete recovery was also seen in 8 patients who had RNFI at registration, but for various reasons did not receive prednisolone. It is unclear whether this finding represents a natural tendency to spontaneous recovery in some cases of RNFI, or if it is a consequence of lack of accuracy in examining the patient either at registration or RFT. The distribution of nerves involved is comparable with what is described in other studies. ${ }^{9}$ The most commonly involved were the ulnar (motor function) and the posterior tibial nerves (sensibility).

Although the occurrence of NFI, and not of leprosy reactions is the focus of this paper, some general figures concerning reactions are presented. Reversal reactions were observed in $0.6 \%$ of the PB patients during MDT (a 6- to 9-month period only), giving an incidence rate of approximately 1 per 100 PYR. The percentage of MB patients 
diagnosed with reversal during MDT (a period ranging from 2 to 3 years) was $14 \%$, giving a $n$ incidence rate of approximately 6 per 100 PYR. The percentage of MB patients diagnosed with ENL during MDT was $2 \cdot 1 \%$, with an incidence rate of approximately 1 per 100 PYR. These figures appear lower than found by Van Brakel et al., ${ }^{9}$ and nearer to figures found in other studies. ${ }^{10,11}$ The lower figures are due to the fact that the cohort in this paper primarily consisted of outpatients, in which reversal reactions were probably underdiagnosed by the attending paramedical staff, causing only the more severe reactions to be registered, referred and treated in hospital. Also the observation period (during MDT only) was shorter than in the studies mentioned. Finally, it must be pointed out that the incidence rate figures for leprosy reactions during MDT are essentially different from those of RNFI during MDT. Leprosy reactions can occur in all patients, regardless the presence of pre-existing NFI. The calculation of incidence rates for leprosy reactions is based on the complete cohorts $\mathrm{PB}$ or MB patients. Incidence rate figures for NFI include only those patients who had no NFI at registration.

In terms of opportunities for intervention and their relative impact on POD, there are some important conclusions to draw. This study clearly shows (again) that most cases with NFI at the completion of MDT treatment already had impairment at the time of registration ( $9.8 \%$ in the $\mathrm{PB}$, and $37.6 \%$ in the MB group). During the time of MDT, another $1.6 \%$ in the $\mathrm{PB}$, and $7.9 \%$ in the MB group are added to those with NFI. Early detection of new leprosy cases obviously will have the largest impact in the prevention of disability; by itself it could prevent disabilities in more than $30 \%$ of all patients. A comprehensive field programme with active case finding should therefore be the main thrust in any leprosy programme. The impact of POD activities during the time that patients receive MDT, i.e. regular examinations, VMT's ST's, and treatment in the field with prednisolone will prevent disabilities in less than $10 \%$ of the cases, according to this study. NFI impairment is also known to occur after completion of MDT. POD activities should also extend into this phase, with sufficient health education to all patients on the signs of early nerve damage and with regular follow-up of patients at risk. The impact of POD after completion of MDT will be another 5 to $10 \%$.

Finally, the figures in this paper suggest that the provision of prednisolone is definitely effective when given appropriately in all indicated cases. Much more effort should be made to determine clear indications for the provision of prednisolone, appropriate techniques for use in the field by paramedical workers to determine early NFI, and effective steroid regimens that can be administered efficiently under field conditions.

\section{References}

${ }^{1}$ Srinivasan H. Deformities and disabilities - unfinished agenda in leprosy work. Lepr Rev, 1995; 66: 193200.

${ }^{2}$ Lienhardt C, Fine PEM. Type 1 reaction, neuritis and disability in leprosy. What is the current epidemiological situation? Lepr Rev, 1994; 65: 9-33.

3 Van Brakel WH. Peripheral neuropathy in leprosy. The continuing challenge. Thesis Universiteit Utrecht, 1994.

4 Richardus JH, Croft RP. Estimating the size of the leprosy problem: the Bangladesh experience. Lepr Rev, 1995; 66: 158-64.

${ }^{5}$ Watson JM. Essential action to minimise disability in leprosy patients. The Leprosy Mission International. London, 1988. 
${ }^{6}$ Van Brakel WH, Khawas IB. Nerve damage in leprosy: an epidemiological and clinical study of 396 patients in west Nepal - part 1. Definitions, methods and frequencies. Lepr Rev, 1994; 65: 204-221.

7 WHO Expert Committee on leprosy, sixth Report. WHO Technical Report series. No. 768. WHO, Geneva, 1988.

${ }^{8}$ WHO. Weekly Epidemiological Record, 1995; 70: 269-76.

9 Van Brakel WH, Khawas IB, Lucas SB. Reactions in leprosy: an epidemiological study of 386 patients in west Nepal. Lepr Rev, 1994; 65: 190-203.

${ }^{10}$ Becx-Bleumink M, Berhe D. Occurrence of reactions, their diagnosis and management in leprosy patients treated with multidrug therapy; experience in the Leprosy Control Program of the All Africa Leprosy and Rehabilitation Training Centre (ALERT) in Ethiopia. Int J Lepr, 1992; 60: 173-84.

${ }^{11}$ Roche PW, Theuvenet WJ, Britton WJ. Risk factors for type I reactions on borderline leprosy patients. Lancet, 1991: 338: 654-6. 